Journal of Fundamental and Applied Sciences

ISSN 1112-9867

Available online at

http://www.jfas.info

\title{
ANTICORROSION POTENTIAL OF HYDRALAZINE FOR CORROSION OF MILD STEEL IN 1M HYDROCHLORIC ACID SOLUTION
}

\author{
B. M. Prasanna ${ }^{1}$, B. M. Praveen*2, Narayana Hebbar ${ }^{3}$, T.V.Venkatesha ${ }^{4}$ \\ ${ }^{1}$ Department of Chemistry, Sri Taralabalu Jagadguru Institute of Technology, \\ Ranebennur, India \\ ${ }^{2}$ Department of Chemistry, Srinivas School of Engineering, Mukka, Mangalore, India \\ ${ }^{3}$ Department of Chemistry, Bearys Institute of Technology, Mangalore, India \\ ${ }^{4}$ Department of Studies in Chemistry, School of Chemical Sciences, Kuvempu University, \\ Shankaraghatta, India
}

Received: 21 February 2015 / Accepted: 07 March 2015 / Published online: 08 March 2015

\begin{abstract}
Anticorrosion potential of mild steel by Hydralazine as corrosion inhibitor for mild steel in $1 \mathrm{M}$ hydrochloric acid was investigated by chemical and electrochemical measurements at 303-333 K temperature. The maximum inhibition efficiency of inhibitor by Weight loss method is around $90 \%$, Tafel polarization method is around $85 \%$; electrochemical impedance spectroscopy measurement around $90 \%$ at $1250 \mathrm{ppm}$ of Hydralazine in. The result shows that the inhibition efficiency increases with I 1M hydrochloric acid. Hydralazine acts as a mixed type inhibitor which inhibits the corrosion of mild steel due to the adsorption on metal surface. This adsorption system obeys the Langmuir adsorption isotherm.Activation parameters explains the effect of temperature with inhibition efficiency of inhibitor molecule.SEM images of inhibited mild steel strips shows a formation of passive protective film over the surface.
\end{abstract}

Keywords: Hydralazine; Weight loss; Mild steel; Activation parameters; SEM,

Author Correspondence, e-mail: bm.praveen@yahoo.co.in

ICID: 1142716 


\section{INTRODUCTION}

Mild steel is most commonly used material in structural and industrial applications due to its superior structural property and thermal stability. It is used under acid and alkaline media for acid pickling, acid descaling, and oil well acidification in industrial applications. During these processes mild steel readily undergoes corrosion. Corrosion inhibition of mild steel in acid solutions has become one of the most urgent and severe challenges in acid pickling process to prevent undesirable metal dissolution and excess acid consumption [1-7] several methods are used to control the corrosion process to avoid the metal dissolution. Among those use of inhibitor is the most convenient method to control the corrosion. The majorities of the well-known corrosion inhibitors are organic heterocyclic compounds, which containing nitrogen, oxygen, phosphorus and sulfur in their functional groups with aromatic and heterocyclic rings [8-18].Through these elements and $\pi$ electrons in heterocyclic rings, inhibitor molecules adsorbed on the metal surface and provide a barrier between metal and corrosive environment, thereby reducing the corrosion rate. Many corrosion inhibitors are generally toxic and generate health hazards. The effectiveness of inhibition depends on the surface charge of the metal, the nature of the medium and chemical structure of the inhibitor molecule such as functional groups, aromaticity, and the p orbital character of the donating electron, steric factor, and electron density at the donor atoms [19-22].

Hydralazine is an anti hypertension drug molecule, which consist of electron rich nitrogen atoms. Through this nitrogen atoms Hydralazine easily adsorbed on the surface of the mild steel in acid media, which gives scope for its study as a efficient corrosion inhibitor. In the present work the inhibiting action of Hydralazine for corrosion of mild steel has been studied by Tafel polarization, impedance spectroscopy, thermodynamic and activation measurements. The surface study was done by SEM analysis at temperature region of $303-333 \mathrm{~K}$ in $1 \mathrm{M} \mathrm{HCl}$ solution.

\section{RESULTS AND DISCUSSION}

\subsection{Weight loss measurements}

The weight loss measurement was conducted for the corrosion inhibition of mild steel in $1 \mathrm{M}$ 
hydrochloric acid in absence and presence of various inhibitor concentrations. The corrosion parameters were computed and reported in Table 1.

Table 1. Corrosion parameters obtained from the weight loss measurement for corrosion of mild steel in $1 \mathrm{M} \mathrm{HCl}$ in absence and Presence of various concentrations of Hydralazine.

Corrosive medium Corrosion rate Inhibition efficiency

\begin{tabular}{ccc}
$\begin{array}{c}\text { of Hydralazine } \\
(\mathbf{p p m})\end{array}$ & $\boldsymbol{v}$ & $\boldsymbol{\eta}_{\mathbf{w}}$ \\
\hline Blank & $\left.\mathbf{g m} / \mathbf{c m}^{\mathbf{2}} \mathbf{h r}\right)$ & $(\%)$ \\
250 & 0.357 & - \\
500 & 0.170 & 52.38 \\
750 & 0.132 & 63.00 \\
1000 & 0.098 & 72.54 \\
1250 & 0.042 & 88.22 \\
\hline
\end{tabular}

A.

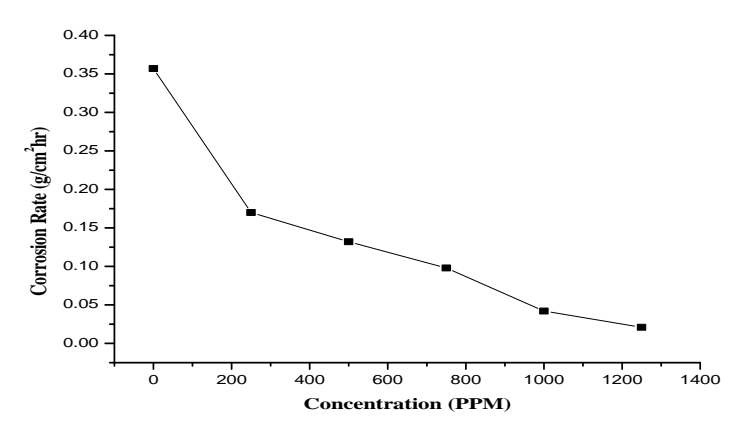

B.

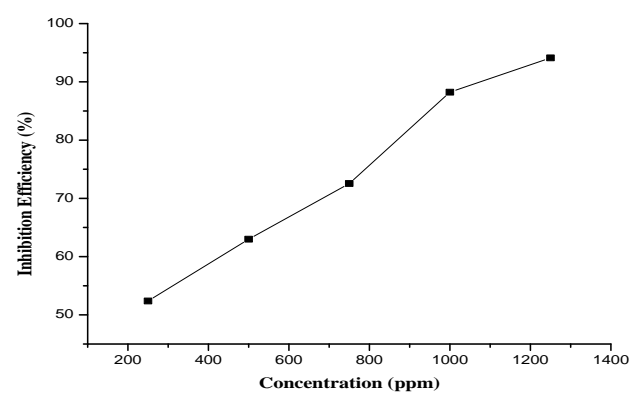

Fig.1.Variation of concentration against (A) Corrosion rate (B) Inhibition efficiency of corrosion inhibition of mild steel in $1 \mathrm{M} \mathrm{HCl}$ in absence and Presence of various concentrations of Hydralazine.

From the Table 1 and Fig.1 suggests the following discussions,

- Corrosion rate decreases with increase of inhibitor concentration (Figure 1A) due to either increase the thickness of adsorption layer or covers the surface of mild steel by the inhibitor molecules. 
- Inhibition efficiency increases with increase of inhibitor concentrations (Figure 1B).The highest value of $94.11 \%$ was obtained at $1250 \mathrm{ppm}$ concentration of Hydralazine.

While considering the above result and discussion Hydralazine acts as a good corrosion inhibitor for mild steel in $1 \mathrm{M} \mathrm{HCl}$ solution.

\subsection{Tafel Polarization measurements}

Tafel Polarization plots were obtained for the corrosion of mild steel in $1 \mathrm{M} \mathrm{HCl}$ solution in absence and presence of various inhibitor concentrations at a temperature region 303-333K. Ploted Tafel plots was described in Fig.2.The Electrochemical corrosion parameters such as corrosion potential $\left(\mathrm{E}_{\mathrm{corr}}\right)$, corrosion current density $\left(\mathrm{i}_{\mathrm{corr}}\right)$, corrosion rate $(v)$ cathodic Tafel slope $(\beta c)$, anodic Tafel slope $(\beta a)$ and inhibition efficiency $\left(\eta_{p}\right)$ obtained from the Tafel polarization measurement were reported in Table 2 . The inhibition efficiency $\left(\eta_{\mathrm{p}}\right)$ was calculated from the fallowing equation.

$$
\eta_{\mathrm{P}}=\frac{\mathrm{i}_{\text {corr }}^{\mathrm{o}}-\mathrm{i}_{\text {corr }}}{\mathrm{i}_{\text {corr }}^{\mathrm{o}}} \times 100 \text {. }
$$

Where, $i^{\mathbf{o}}$ corr and $i_{\text {corr }}$ are corrosion current density in the absence and presence of inhibitor respectively.

From Table 2.suggests that the close observation of results obtained from the Tafel polarization method. Whenever inhibitor concentration increases as on 250-1250 ppm of Hydralazine concentration in $1 \mathrm{M} \mathrm{HCl}$ solution at 303-333K following discussions was listed as follows,

- The Corrosion rate $(v)$ was gradually decreases due to the adsorption of the inhibitor molecule on the surface of the mild steel which retards the corrosion process. So that the inhibition efficiency of the inhibitor molecule increases. 


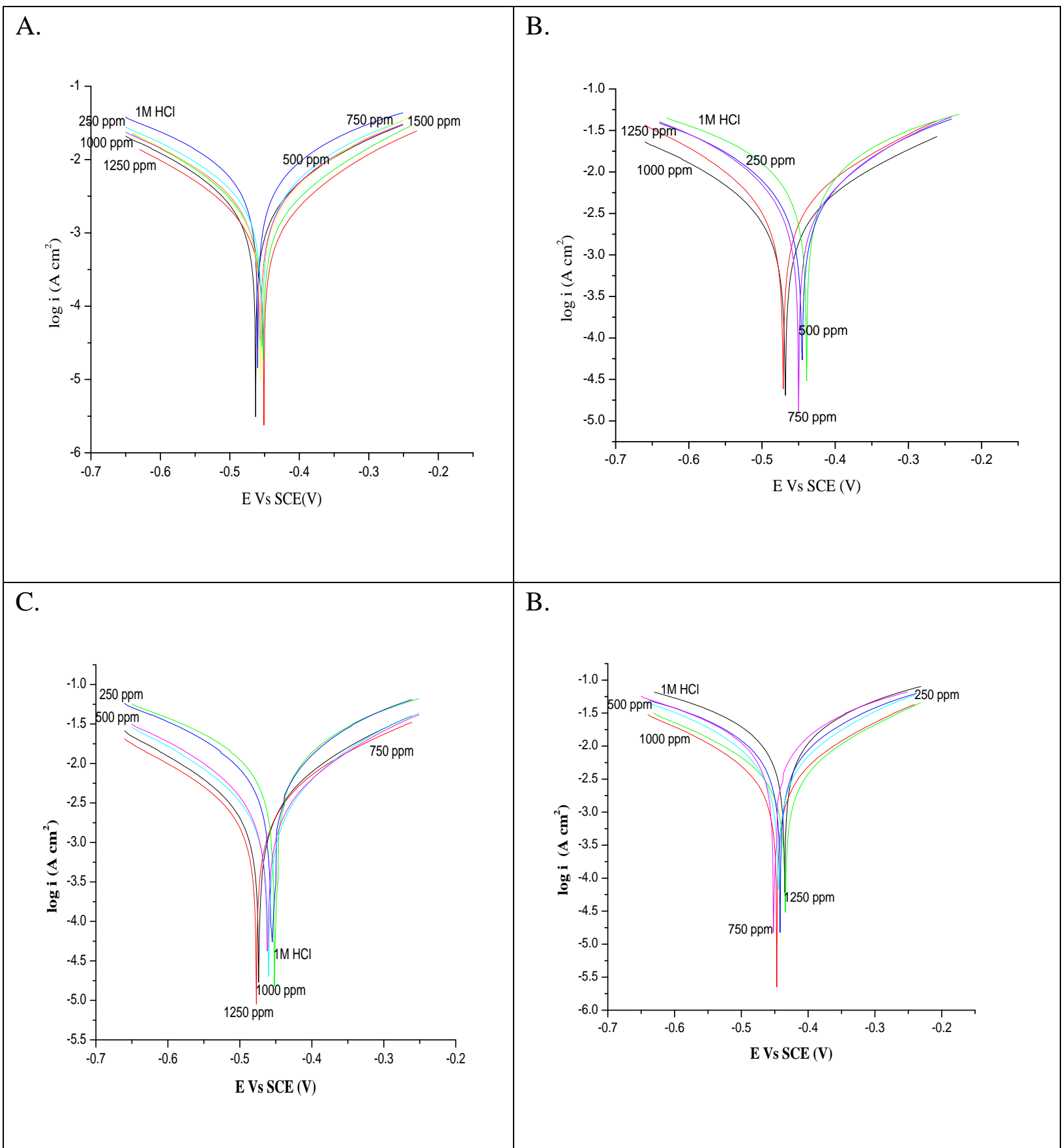

Fig.2. Tafel polarization plots for the corrosion of mild steel in $1 \mathrm{M} \mathrm{HCl}$ in the absence and presence of various inhibitor concentrations at (A) $303 \mathrm{~K}$ (B) $313 \mathrm{~K}$ (C) $323 \mathrm{~K}$ (D) $333 \mathrm{~K}$ temperatures. 
Table 2. Electrochemical Tafel polarization parameters for the corrosion of mild steel in absence and presence of various concentrations of Hydralazine in $1 \mathrm{M} \mathrm{HCl}$.

\begin{tabular}{|c|c|c|c|c|c|c|c|}
\hline \multirow[t]{4}{*}{$(\mathbf{K})$} & $\begin{array}{c}\text { Inhibitor } \\
\text { concentratio } \\
\mathbf{n} \\
\mathbf{C} \\
\\
\text { (ppm) }\end{array}$ & $\begin{array}{c}\text { Corrosion } \\
\text { potential } \\
\text { Ecorr } \\
\text { (V) }\end{array}$ & $\begin{array}{c}\text { Corrosion } \\
\text { current density } \\
\text { density } \\
\text { i corr } \\
\left(\mathrm{A} \mathrm{cm}^{-2}\right)\end{array}$ & $\begin{array}{c}\text { Corrosion } \\
\text { rate } \\
v_{\text {corr }}\end{array}$ & $\begin{array}{c}\text { Cathodic } \\
\text { slope } \\
\beta c\end{array}$ & $\begin{array}{c}\text { Anodic } \\
\text { slope } \\
\beta \mathbf{a}\end{array}$ & $\begin{array}{l}\text { Inhibition } \\
\text { efficiency }\end{array}$ \\
\hline & Blank & -0.480 & 0.259 & 50.75 & -5.800 & 5.900 & - \\
\hline & 250 & -0.466 & 0.145 & 28.50 & -6.298 & 6.602 & 30.50 \\
\hline & 500 & -0.460 & 0.120 & 23.47 & -6.425 & 6.638 & 53.66 \\
\hline \multirow[t]{6}{*}{303} & 750 & -0.456 & 0.106 & 20.82 & -6.639 & 7.128 & 59.07 \\
\hline & 1000 & -0.453 & 0.077 & 15.00 & -6.518 & 6.710 & 70.02 \\
\hline & 1250 & -0.451 & 0.059 & 13.50 & -6.809 & 7.377 & 77.22 \\
\hline & Blank & -0.471 & 0.427 & 83.53 & -5.279 & 5.200 & - \\
\hline & 250 & -0.468 & 0.229 & 44.87 & -6.140 & 6.270 & 46.37 \\
\hline & 500 & -0.462 & 0.208 & 40.75 & -6.400 & 6.530 & 51.28 \\
\hline \multirow[t]{6}{*}{313} & 750 & -0.456 & 0.160 & 31.43 & -6.408 & 6.290 & 62.50 \\
\hline & 1000 & -0.452 & 0.134 & 26.24 & -6.134 & 6.020 & 68.60 \\
\hline & 1250 & -0.450 & 0.126 & 17.50 & -6.526 & 6.042 & 70.49 \\
\hline & Blank & -0.458 & 0.829 & 84.03 & -5.282 & 5.721 & - \\
\hline & 250 & -0.453 & 0.293 & 57.38 & -6.035 & 6.290 & 64.60 \\
\hline & 500 & -0.448 & 0.152 & 45.00 & -6.621 & 7.180 & 81.20 \\
\hline \multirow[t]{7}{*}{323} & 750 & -0.445 & 0.136 & 26.75 & -6.448 & 6.740 & 83.50 \\
\hline & 1000 & -0.443 & 0.129 & 25.28 & -6.283 & 6.602 & 84.40 \\
\hline & 1250 & -0.440 & 0.122 & 23.96 & -6.130 & 6.360 & 85.20 \\
\hline & Blank & -0.435 & 0.840 & 105.0 & -5.230 & 5.620 & - \\
\hline & 250 & -0.429 & 0.377 & 73.79 & -5.570 & 6.050 & 55.11 \\
\hline & 500 & -0.424 & 0.248 & 67.00 & -6.210 & 6.630 & 70.40 \\
\hline & 750 & -0.414 & 0.210 & 60.50 & -5.670 & 6.260 & 74.90 \\
\hline \multirow[t]{2}{*}{333} & 1000 & -0.410 & 0.178 & 52.00 & -6.279 & 6.605 & 78.80 \\
\hline & 1250 & -0.404 & 0.156 & 47.10 & -5.970 & 6.510 & 80.80 \\
\hline
\end{tabular}

- Corrosion potential $\left(\mathrm{E}_{\mathrm{corr}}\right)$ value of inhibited solution was slight changed with respect to the uninhibited solution, if the value of $\mathrm{E}_{\text {corr }}$ value is less than $\pm 85 \mathrm{mV}$ indicates that the 
inhibitor acts as mixed type [23]. Presently the study records around $30 \mathrm{mV}$ was a maximum displacement of $\mathrm{E}_{\mathrm{corr}}$ indicates that the Hydralazine acts as mixed type inhibitor for the corrosion of mild steel in $1 \mathrm{~m} \mathrm{HCl}$ solution. Hence the increase in inhibition efficiency observed at higher inhibitor concentration indicates that more inhibitor molecules are adsorbed on the metal surface thus providing wider surface coverage and these compounds inhibits the corrosion process.

\subsection{Electrochemical Impedance spectroscopy (EIS)}

Corrosion inhibition of mild steel in $1 \mathrm{M} \mathrm{HCl}$ solution was investigated in presence and absence of Hydralazine by electrochemical impedance spectroscopic measurement. This method provides information about the kinetics of the electrode processes and simultaneously about the surface properties of the investigated systems. Fig.3 shows Nyquist plots recorded for the corrosion of steel in $1 \mathrm{M} \mathrm{HCl}$. In this plots, the impedance spectra consists of high-frequency (HF) depressed semicircles are observed. The electrochemical impedance parameters computed by fitting into an equivalent circuit is as shown in Fig.4. Meassured EIS parameters such as polarization resistance $(R p)$, double-layer capacitance $\left(C_{d l}\right)$ and the inhibition efficiency $\left(\eta_{z}\right)$ were reported in Table 3. Inhibition efficiency $\left(\eta_{z}\right)$ was calculated using the following equation [24].

$$
\eta_{\mathrm{Z}}=\frac{\mathrm{R}_{\mathrm{p}}-\mathrm{R}_{\mathrm{p}}^{\mathrm{o}}}{\mathrm{R}_{\mathrm{p}}} \times 100
$$

Where, $R_{p}$ and $R_{p}{ }^{0}$ are polarization resistance values in the presence and absence of inhibitor. The double layer capacitance values $\left(\mathrm{C}_{\mathrm{dl}}\right)$ were evaluated by the formula

$$
\mathrm{C}_{\mathrm{dl}}=\left(\mathrm{QR}_{\mathrm{ct}}^{1-\mathrm{n}}\right)^{1 / \mathrm{n}}
$$

Where $Q$ is the constant phase element (CPE) $\left({ }^{-1} \mathrm{~S}^{\mathrm{n}} \mathrm{cm}^{-2}\right)$ and $n$ is the CPE exponent which gives details about the degree of surface inhomogeneity. 
A.

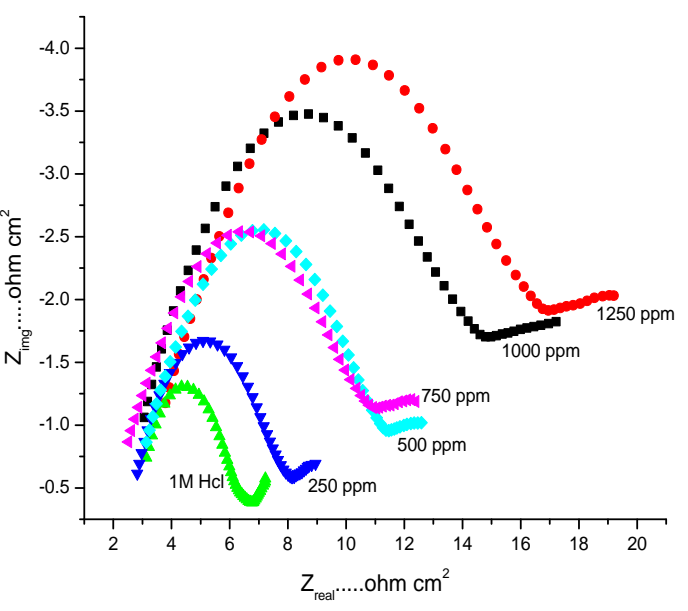

C.

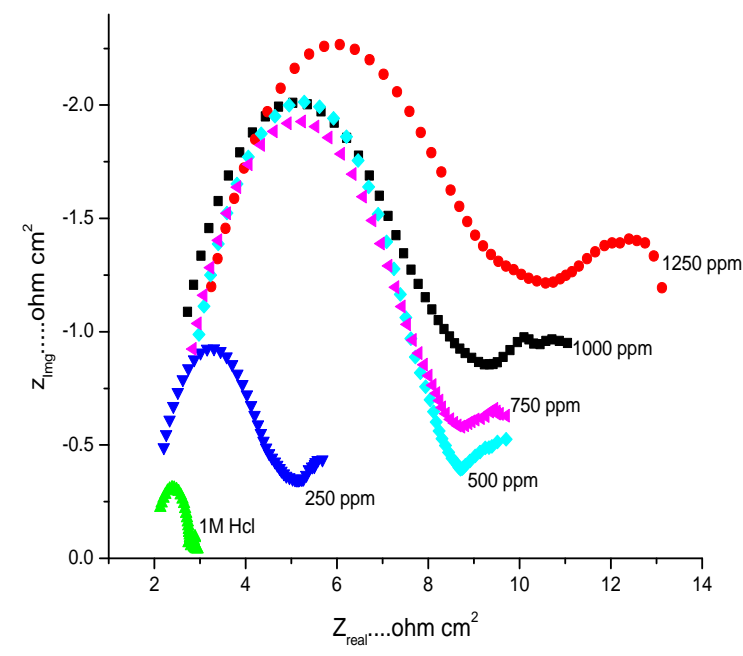

B.

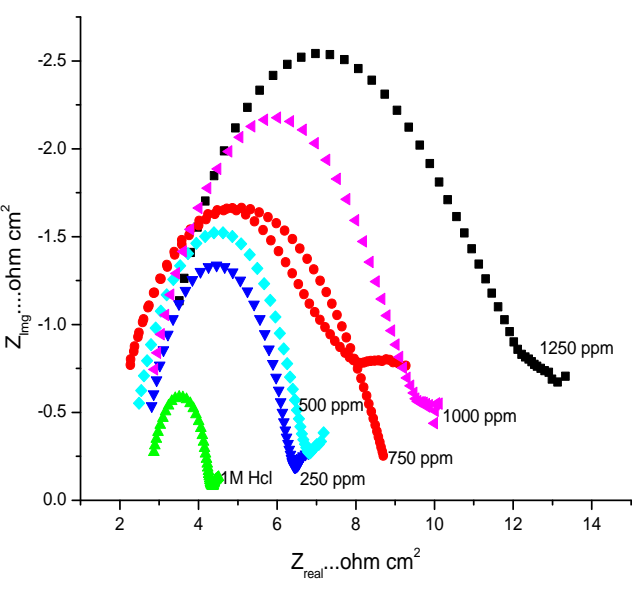

D.

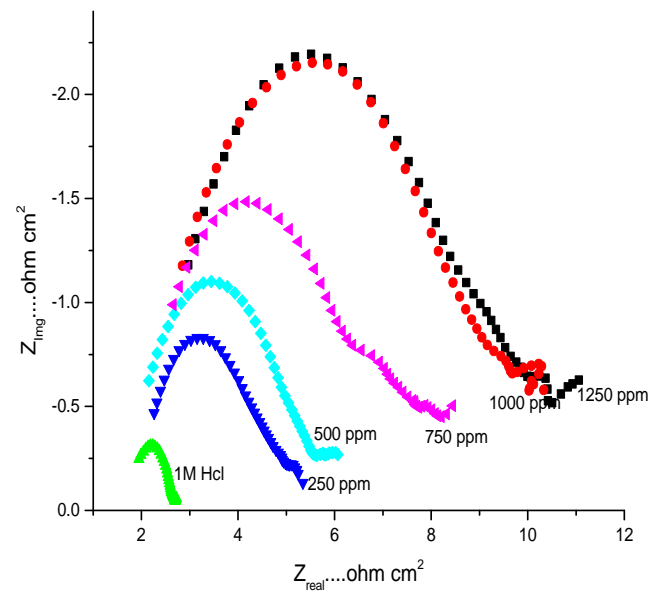

Fig.3. Nyquist Plots for mild steel in $1 \mathrm{M} \mathrm{HCl}$ in the absence and presence of different inhibitor concentrations at (A) $303 \mathrm{~K}$ (B) $313 \mathrm{~K}$ (C) $323 \mathrm{~K}$ (D) $333 \mathrm{~K}$ temperatures.

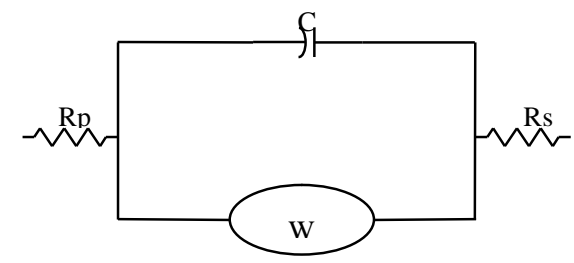

Fig.4. Equivalent circuit used to fit impedance data. 
Table 3. Electrochemical impedance spectroscopy parameters for corrosion of mild steel in absence and presence of various concentrations of Hydralazine in $1 \mathrm{M} \mathrm{HCl}$.

\begin{tabular}{|c|c|c|c|c|c|}
\hline $\begin{array}{c}\text { Temperature } \\
\text { (K) }\end{array}$ & $\begin{array}{c}\text { Inhibitor con }^{\mathbf{n}} \\
\quad(\mathbf{p p m})\end{array}$ & $\begin{array}{c}\mathbf{R}_{\mathbf{p}} \\
\left(\begin{array}{c}\mathbf{c m}^{2} \\
)\end{array}\right)\end{array}$ & $\begin{array}{c}C_{d l} \\
\left(\mu \mathrm{F} \mathrm{cm}^{-2}\right)\end{array}$ & $\begin{array}{c}\eta_{\mathrm{z}} \\
(\%)\end{array}$ & $\begin{array}{c}\text { Surface } \\
\text { coverage } \\
(\theta)\end{array}$ \\
\hline \multirow{6}{*}{303} & Blank & 4.48 & 6596 & - & \\
\hline & 250 & 6.28 & 1783 & 28.66 & 0.286 \\
\hline & 500 & 9.84 & 1270 & 54.48 & 0.544 \\
\hline & 750 & 10.39 & 1035 & 56.88 & 0.568 \\
\hline & 1000 & 14.58 & 576 & 69.27 & 0.692 \\
\hline & 1250 & 16.26 & 547 & 72.44 & 0.724 \\
\hline \multirow{6}{*}{313} & Blank & 1.68 & 5271 & - & \\
\hline & 250 & 4.033 & 2839 & 58.34 & 0.583 \\
\hline & 500 & 4.797 & 2694 & 65.66 & 0.656 \\
\hline & 750 & 7.11 & 1598 & 76.38 & 0.763 \\
\hline & 1000 & 10.3 & 488 & 83.60 & 0.836 \\
\hline & 1250 & 12.1 & 438 & 86.1 & 0.861 \\
\hline \multirow{6}{*}{323} & Blank & 0.881 & 5162 & - & \\
\hline & 250 & 3.639 & 1097 & 75.79 & 0.757 \\
\hline & 500 & 6.607 & 1072 & 86.60 & 0.866 \\
\hline & 750 & 6.990 & 661 & 87.41 & 0.874 \\
\hline & 1000 & 8.490 & 286 & 89.62 & 0.896 \\
\hline & 1250 & 10.30 & 118 & 91.44 & 0.914 \\
\hline \multirow{6}{*}{333} & Blank & 0.943 & 3536 & - & \\
\hline & 250 & 3.250 & 1270 & 71.06 & 0.710 \\
\hline & 500 & 4.120 & 1250 & 77.12 & 0.771 \\
\hline & 750 & 6.630 & 428 & 85.70 & 0.857 \\
\hline & 1000 & 8.184 & 228 & 88.40 & 0.884 \\
\hline & 1250 & 8.361 & 158 & 88.70 & 0.887 \\
\hline
\end{tabular}

The electrochemical impedance spectrum (EIS) consists of semicircles with their centers below the real axis described as Fig.3, the concentration of inhibitor increases as on 250-1250 ppm of Hydralazine, few discussions was observed as follows,

- The diameter of the semicircle (Rp) was increases with respect to the uninhibited solution due to the charge transfer process during the metal dissolution. 
- The decrease of electrical double layer $\left(\mathrm{C}_{\mathrm{dl}}\right)$ value indication of increasing the thickness of the electrical double layer, which retards the corrosion process.

- Inhibition efficiency $\left(\eta_{z}\right)$ was also increases with increase in the inhibitor concentration. Inhibition efficiency increases with increase of temperature from $303 \mathrm{k}$ to $323 \mathrm{~K}$ due to the adsorption process has a dominant role rather than the desorption process.

Inhibition efficiency obtained from EIS method was in good agreement with Tafel polarization method, which is as shown in the Figure 5.

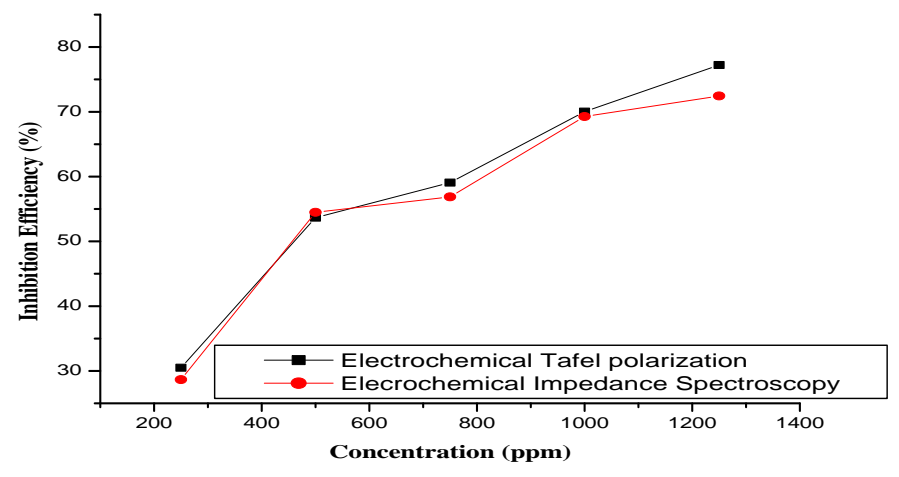

Fig.5. Variation of concentration against inhibition efficiency

\subsection{Adsorption Isotherm and thermodynamic parameters:}

The mechanism of corrosion inhibition can be explained on the basis of adsorption behavior of inhibitor for the corrosion of mild steel in $1 \mathrm{M} \mathrm{HCl}$ at temperature range 303-333 K.Data obtained by the EIS method was used to investigate the adsorption isotherm. The degree of surface coverage $(\theta)$ for different molar concentrations of the inhibitor $\left(C_{\text {inhi }}\right)$ has been evaluated. The degree of surface coverage $(\theta)$ calculated as follows

$$
\theta=\frac{\eta_{z}}{100}
$$

where $\eta_{z}$ was the percentage of inhibition efficiency. Calculated $\theta$ values were reported in Table 4.Various adsorption isotherms can be used to assess the adsorption behavior of the inhibitor on the metal surface. While getting the regression co-efficient $\left(\mathrm{R}^{2}\right)$ value of the straight lines almost near to unity was getting, corresponding adsorption isotherm was a best 
fit for the adsorption process. Langmuir adsorption isotherm was found to be the best description fit to the adsorption behavior of the Hydralazine on mild steel in $1 \mathrm{M} \mathrm{HCl}$. According to this isotherm, a straight line with correlation co-efficient was greater than 0.9 and almost nearly equal to 1.0 was obtained on plotting $C_{\text {inhil }} \theta$ against $C_{\text {inhi }}$ as shown in Fig.6. The degree of surface coverage $(\theta)$ is related to inhibitor concentration $\left(\mathrm{C}_{\mathrm{inhi}}\right)$ is given by the fallowing equation,

$\mathrm{C}_{\text {inhi }} / \theta=1 / \mathrm{K}_{\mathrm{ads}}+\mathrm{C}$

where, $\mathrm{K}_{\mathrm{ads}}$ is equilibrium constant of the equilibrium adsorption process. This isotherm assumes that the adsorbed molecule occupies only one site and it does not interact with other adsorbed species.

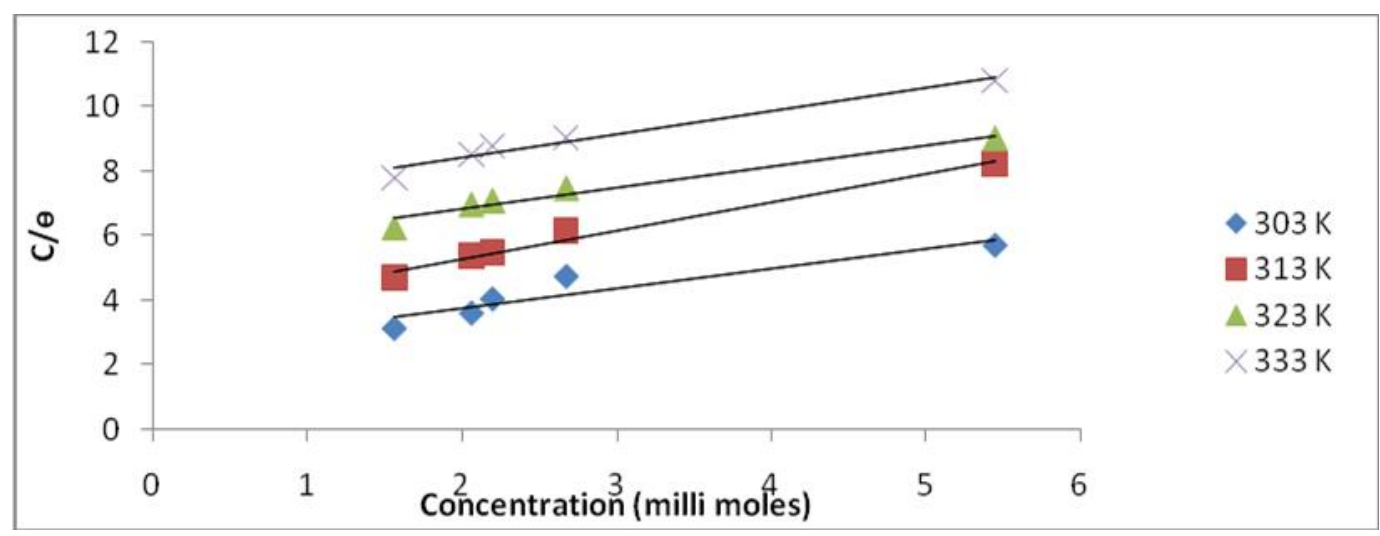

Fig.6. Langmuir adsorption plot of mild steel in $1 \mathrm{M} \mathrm{HCl}$ solution containing different concentrations of Hydralazine at different temperatures.

The $K_{a d s}$ values can be calculated from the intercept lines on the $C_{\text {inhi }} / \theta$ axis. This is related to the standard free energy of adsorption $\left({ }^{\Delta} \mathrm{G}_{\mathrm{ads}}\right)$ by equation,

$$
\mathrm{G}_{\mathrm{ads}}=-\mathrm{RT} \ln \left(55.5 \mathrm{~K}_{\mathrm{ads}}\right)
$$

where, $\mathrm{R}$ is the gas constant and $\mathrm{T}$ is the absolute temperature. 55.5 is the concentration of water in solution in $\mathrm{mol} / \mathrm{L}$.

The enthalpy of adsorption was deduced from the Gibbs Helmholtz equation as fallows.

$$
\left(\frac{\partial G / T}{\partial T}\right)_{p}=-\frac{H}{T^{2}}
$$




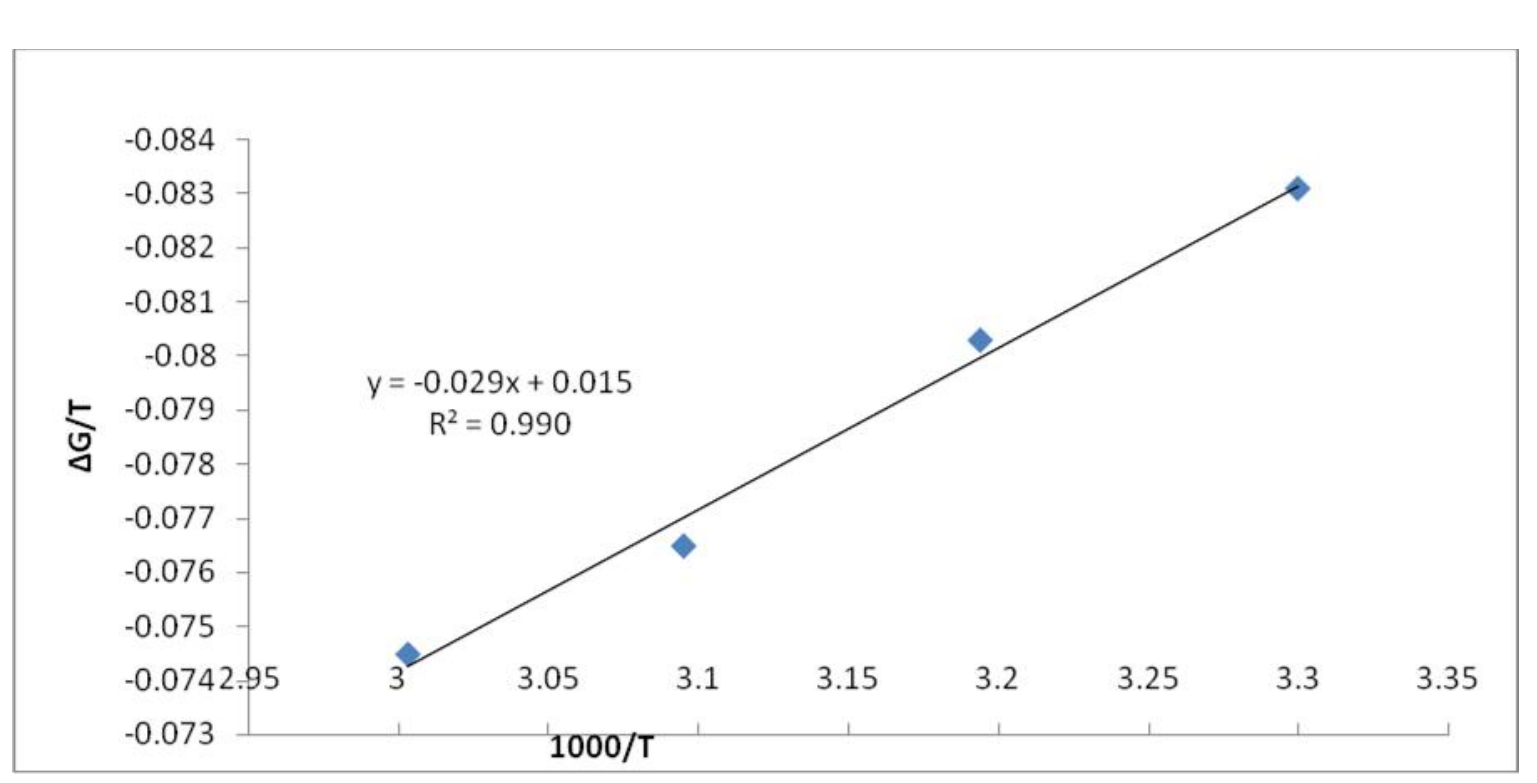

Fig.7. Adsorption isotherm plot for $\mathrm{G}_{\mathrm{ads}} / \mathrm{T}$ Vs $1 / \mathrm{T}$.

where $\mathrm{R}$ is the universal gas constant, $\mathrm{T}$ is the absolute temperature and 55.5 is the molar concentration of water in the solution. This equation can be rearranged to give the following equation

$\Delta \mathrm{S}_{\text {ads }}^{0}=\left(\Delta \mathrm{H}_{\text {ads }}^{0}-\Delta \mathrm{G}_{\text {ads }}^{0}\right) / \mathrm{T}$

A plot of $\mathrm{G}^{0}{ }_{\text {ads }} / \mathrm{T}$ versus $1 / \mathrm{T}$ gives straight lines as shown in Figure 7, with the slope equal to $-\mathrm{S}_{\text {ads }}^{0}$, and the value of $\mathrm{H}_{\text {ads }}^{0}$ can be calculated from the intercept. The computed thermodynamic parameters such as $\mathrm{K}_{\mathrm{ads}}$, Gibbs free energy change of adsorption $\left(\Delta \mathrm{G}^{0}{ }_{\mathrm{ads}}\right)$, enthalpy change of adsorption ( $\mathrm{H}^{0}$ ads $)$ and entropy change of adsorption ( $\mathrm{S}_{\text {ads }}^{0}$ ) were reported in Table 4.

Table 4. Thermodynamic Parameters for the corrosion of mild steel in $1 \mathrm{M} \mathrm{HCl}$ in the presence different Concentration of Hydralazine at different temperatures.

\begin{tabular}{ccccc}
\hline $\begin{array}{c}\text { Temperature } \\
(\mathbf{K})\end{array}$ & $\begin{array}{c}\mathbf{K}_{\text {ads }} \\
(\mathbf{k J} / \mathbf{~ m o l})\end{array}$ & $\begin{array}{c}\mathbf{G}^{\mathbf{0}} \text { ads } \\
(\mathbf{k J} / \mathbf{~ m o l})\end{array}$ & $\begin{array}{c}\mathbf{H}^{\mathbf{0}}{ }_{\text {ads }} \\
(\mathbf{k J} / \mathbf{m o l})\end{array}$ & $\begin{array}{c}\mathbf{S}^{\mathbf{0}}{ }_{\text {ads }} \\
\mathbf{J} / \mathbf{m o l} / \mathbf{K}\end{array}$ \\
\hline 303 & 395.2 & -25.18 & -29.00 & -12.6 \\
313 & 284.0 & -25.15 & -29.00 & -12.3 \\
323 & 189.9 & -24.74 & -29.00 & -13.1 \\
333 & 142.5 & -24.84 & -29.00 & -12.4 \\
\hline
\end{tabular}


From the close observation of thermodynamic parameters (Table 4), the following discussions were discussed,

- $\mathrm{K}_{\mathrm{ads}}$ value indicates that the strong adsorption of inhibitor on the metal surface, higher its value implies that the inhibitor shows better inhibition efficiency [25].In this work $\mathrm{K}_{\mathrm{ads}}$ value more in $303 \mathrm{~K}$, but it was decreases with increase in temperature suggested that the desorption process has dominant role than adsorption process.

- $G_{\text {ads }}^{0}$ value of $-20 \mathrm{~kJ} / \mathrm{mol}$ or lower indicates electrostatic interaction (physisorption), while those around $-40 \mathrm{~kJ} / \mathrm{mol}$ or higher are generally accepted to form a coordinate type of bond (chemisorption) [26].In this present work $G_{\text {ads }}^{0}$ value is around $-25 \mathrm{~kJ} /$ mol indicates that the adsorption of Hydralazine involves mixture of physisorption and chemisorptions and negative sign suggests that the inhibitor adsorbed on the surface of the mild steel spontaneously.

- The negative value of enthalpy of adsorption $\left(\mathrm{H}_{\text {ads }}^{0}\right)$ with a value $-29 \mathrm{~kJ} / \mathrm{mol}$, suggests that the adsorption process is exothermic. Because an exothermic adsorption process involves both physisorption and chemisorptions. The positive value of entropy of adsorption ( $S_{\mathrm{ads}}$ ) with a value in around $-12 \mathrm{~J} / \mathrm{mol} / \mathrm{K}$ indicates that an increase in disorder takes places on going from reactants to the metal-adsorbed reaction complex.

\section{5 .Activation Parameters}

Activation parameters play an important role to understanding the inhibition mechanism. Results obtained from electrochemical Tafel polarization measurements were used to investigate the activation parameters in the temperature range of $303-333 \mathrm{~K}$ in the absence and presence of different concentrations of Hydralazine for mild steel in $1 \mathrm{M} \mathrm{HCl}$.The apparent activation energy $\left(E^{*}\right)$ for mild steel in $1 \mathrm{M} \mathrm{HCl}$ is calculated by using Arrhenius equation as fallows.

$\ln v_{\text {corr }}=\ln \mathrm{A}-\frac{E_{\sigma^{*}}^{*}}{\mathrm{RT}}$

where $v_{\text {corr }}$ is the corrosion rate, $\mathrm{R}$ is the universal gas constant, $T$ is the absolute temperature, 
and $A$ is the Arrhenius pre-exponential factor. Arrhenius plot of corrosion rate $\left(v_{\text {corr }}\right)$ versus $1 / \mathrm{T}$ for the corrosion of mild steel in $1 \mathrm{M} \mathrm{HCl}$ solution in the absence and presence of different concentration of Hydralazine at $303-333 \mathrm{~K}$ is as shown in Fig.8.

From the Fig 8., the slope $\left(-E^{*} / \mathrm{R}\right)$ of each individual straight line was determined, and the activation energy was calculated by using the expression $E_{\mathrm{a}}=$ slope $\times \mathrm{R}$. The calculated values of apparent activation energy $\left(E^{*}\right)$ and Arrhenius pre-exponential factor (A) can be summarized in Table 5.

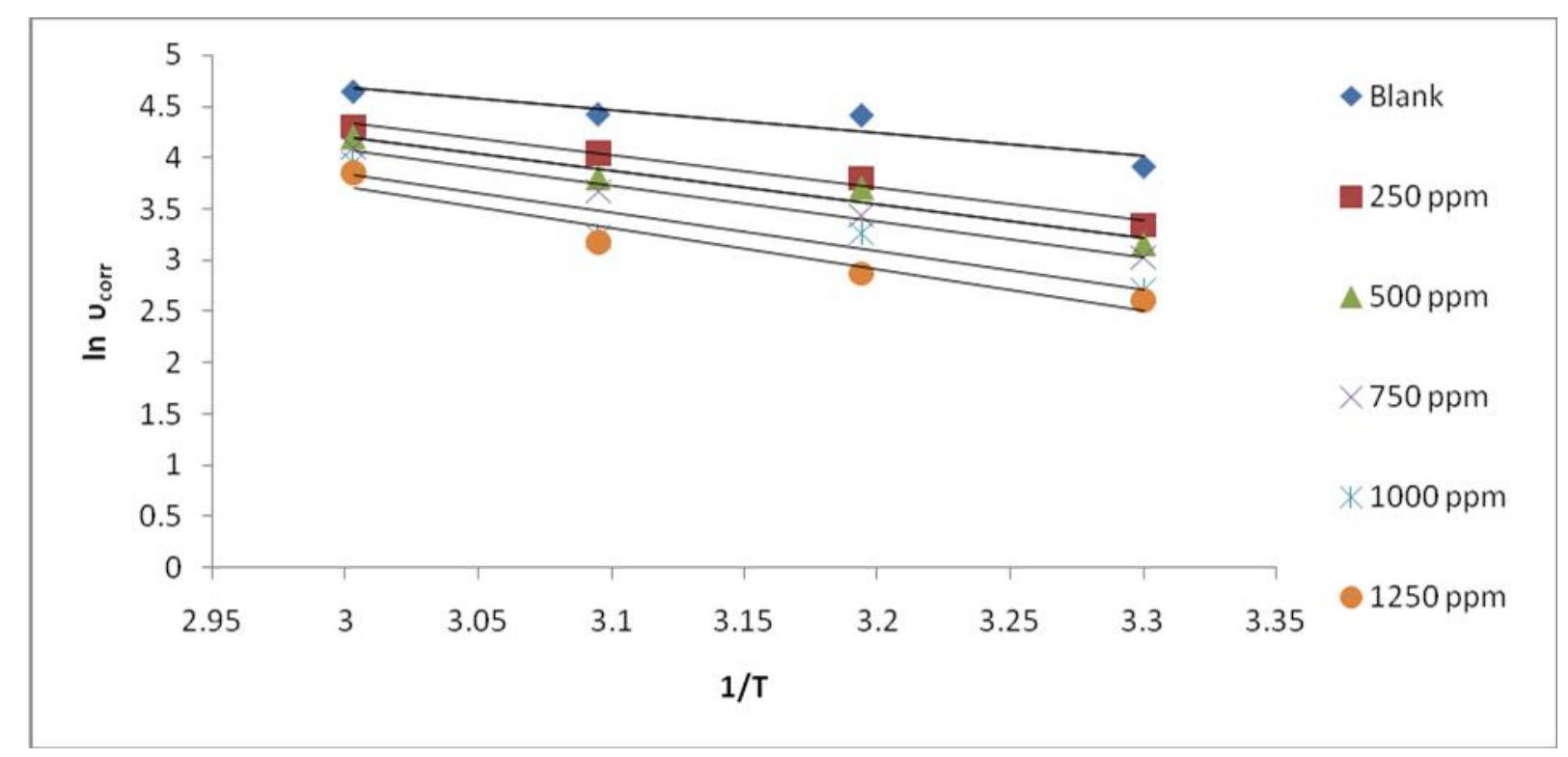

Fig.8. Arrhenius plot for mild steel in the absence and presence of different Concentrations of Hydralazine in $1 \mathrm{M} \mathrm{HCl}$.

The change in enthalpy $\left(H^{*}\right)$ and entropy $\left(S^{*}\right)$ of activation were calculated by the transition-state equation given below [27].

$\left.\frac{\ln v \cot T}{T}=\left[\ln \frac{R}{N h}+\frac{\Delta S^{*}}{R}\right]-\frac{\Delta H^{*}}{R}\right]$

Where $\mathrm{N}$ is the Avogadro's number and $h$ is the Planck's constant. The plots of $\ln \left(v_{\text {corr }} / \mathrm{T}\right)$ versus 1/T are depicted in Fig.9. Straight lines were obtained with a slope of $-H$ and $S$ values were calculated from the intercepts of $\ln \left(v_{\text {corr }} / T\right)$ axis and are given in Table 5 . The positive sign of the enthalpy $\Delta \mathrm{H}^{*}$ reflects the endothermic nature of the mild steel 
dissolution process. The negative value of the entropy of activation $\Delta S^{*}$ gradually decreases with increase the concentrations of Hydralazine inhibitor for mild steel in $1 \mathrm{M} \mathrm{HCl}$, which indicates that the formation of the activated complex in the rate determining step represents an association rather than a dissociation step, meaning that a decrease in disorder takes place during the course of the transition from reactants to activated complex.

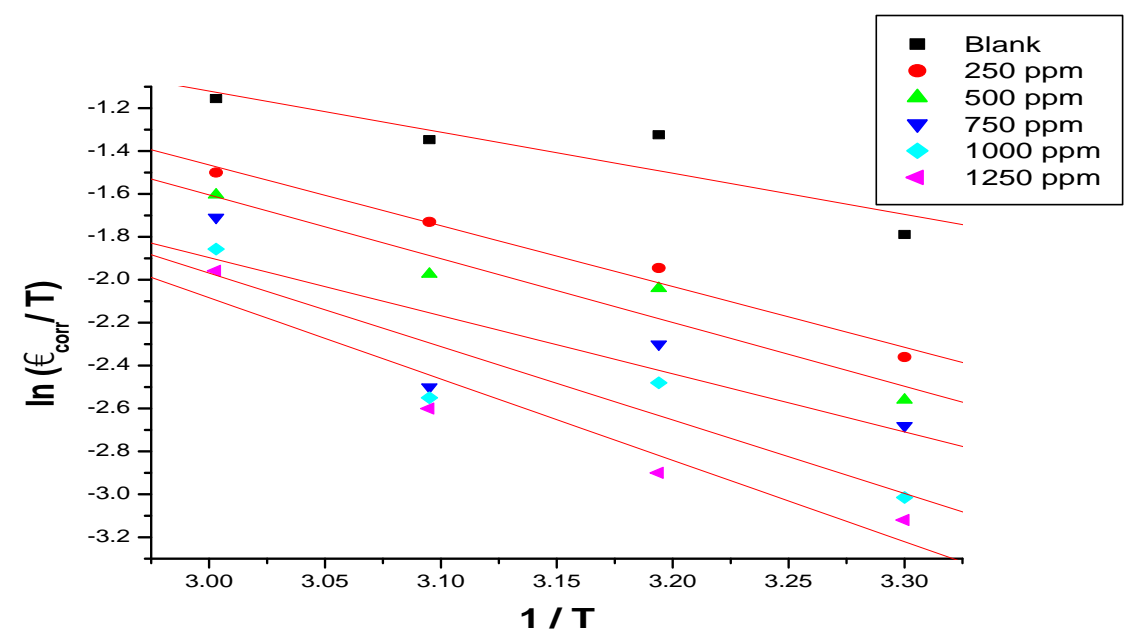

Fig.9.Trasition State plot for mild steel in the absence and presence of different concentrations of Hydralazine in $1 \mathrm{M} \mathrm{HCl}$.

Table 5. Activation parameters for Mild Steel in the absence and Presence of different concentrations of Hydralazine in $1 \mathrm{M} \mathrm{HCl}$.

\begin{tabular}{|c|c|c|c|c|}
\hline $\begin{array}{c}\text { Inhibitor } \\
\text { Concentration } \\
(\text { ppm })\end{array}$ & $\begin{array}{c}\text { Apparent } \\
\text { activation } \\
\text { energy } \\
\left(\mathbf{E}_{\mathbf{a}} *\right) \\
(\mathrm{kJ} / \mathrm{mol})\end{array}$ & $\begin{array}{c}\text { Arrhenius } \\
\text { pre-expone } \\
\text { ntial } \\
\text { constant }(\mathbf{k J} \\
\left.\text { mol }^{-1}\right)\end{array}$ & $\begin{array}{c}\text { Enthalpy of } \\
\text { activation } \\
\left(\mathbf{H}^{*}\right) \\
\left(\mathbf{k J} \mathrm{mol}^{-1}\right)\end{array}$ & $\begin{array}{c}\text { Entropy of } \\
\text { activation } \\
\left(\mathbf{S}^{*}\right) \\
\left(\mathbf{J ~ m o l}^{-1} \mathbf{K}^{-1}\right)\end{array}$ \\
\hline Blank & 18.62 & $8.93 \times 10^{3}$ & 15.92 & -22.29 \\
\hline 250 & 26.28 & $10.04 \times 10^{5}$ & 23.55 & -19.88 \\
\hline 500 & 26.60 & $12.89 \times 10^{5}$ & 24.70 & -19.60 \\
\hline 750 & 28.93 & $20.22 \times 10^{5}$ & 22.51 & -20.69 \\
\hline 1000 & 31.11 & $34.71 \times 10^{5}$ & 28.45 & -18.61 \\
\hline 1250 & 33.80 & $82.02 \times 10^{5}$ & 31.51 & -17.63 \\
\hline
\end{tabular}


From the activation parameters following discussions were discussed,

- From the Arrhenius equation (from $\mathrm{eq}^{\mathrm{n}}$ no.9) corrosion rate affects both $E^{*}{ }_{a}$ and A values.

- The energy of activation $\left(E^{*}\right)$ increases with increase in concentration of Hydralazine due to the inhibitor molecule strongly adsorbed on the surface of the mild steel by blocking the corrosion sites. Energy of activation of inhibited solution was greater than that of the uninhibited solution.

- The Arrhenius pre-exponential factor $(A)$ directly relates with number of active sites covered by the inhibitor molecule. In this work Arrhenius pre-exponential factor drastically changes in the presence of inhibitor than that in the absence of inhibitor, suggests which retards the corrosion process.

- The positive sign of heat of activation $\left(\mathrm{H}^{*}\right)$ indicates that the endothermic nature of steel dissolution process. The values were found for inhibited solution as around $25 \mathrm{~kJ}$ $\mathrm{mol}^{-1}$ which is greater than that of uninhibited solution $\left(15.92 \mathrm{~kJ} \mathrm{~mol}^{-1}\right)$.

- In this present work entropy of activation decreases with increases the inhibitor concentration. Such variation is associated with the ordering and disordering of inhibitor molecules on the mild steel surface. The decreased entropy of activation in the presence of inhibitor indicated that disorderness is decreases on going from reactant to activated complex.

\subsection{Quantum Chemical Parameters}

Quantum chemical parameters are a best tool to investigate the structural, electronic properties of the inhibitor molecule and their inhibition action on metal surface. Quantum chemical parameters of Hydralazine were carried out by using parametric 3 (PM3) method. Programme used for this analysis was done by Hyperchem 7.5 package program. The computed quantum chemical parameters such as energies of the highest occupied molecular orbital $\left(\mathrm{E}_{\mathrm{HOMO}}\right)$ and the lowest unoccupied molecular orbital ( $\left.\mathrm{E}_{\mathrm{LUMO}}\right)$, energy gap ( $\mathrm{E}=\mathrm{E}_{\mathrm{LUMO}}$ - Eномо) and the dipole moment ( ) were reported in Table 6.

According to the frontier molecular orbital theory, an interaction between frontiers orbital 
(HOMO and LUMO) of reacting species, which formed transition state is due to an interaction with metal. Energy of HOMO is often associated with the electron donating ability of a molecule to the vacant d-orbital of the metal occupies lower energy. Higher or increasing values of the Еномо facilitate adsorption process of inhibitor on the metal surface.The energy of the lowest unoccupied molecular orbital,ELUMO indicates the ability of accepting electrons to molecule.The lower the value of $\mathrm{E}_{\mathrm{LUMO}}$, which easier acceptance of electrons. As the energy gap between HOMO and LUMO decreases, the interaction between inhibitor and metal is stronger, this gives good inhibition efficiency.

In the present study higher value of $\mathrm{E}_{\text {номо }}(-8.572 \mathrm{eV})$ indicates, which easily donates electrons to the acceptor with lower energy, lower value of $E_{\text {LUMO }}(-0.748 \mathrm{eV})$, which indicates that the easy acceptance of electrons. The lower energy gap value $(7.824 \mathrm{eV})$ is clears that Hydralazine shows a good inhibition effect on corrosion of mild steel[28]. The HOMO and LUMO energy state of Hydralazine was calculated by the strcture as in Fig. 10.

The dipole moment ( ) is another parameter to explain the electronic distribution in a molecule. Higher the value of dipole moment, higher is the extent of polarization, and greater is the tendency of donation of electrons to the metal surface. In the present study, Hydralazine shows good inhibition efficiency of corrosion of mild steel.

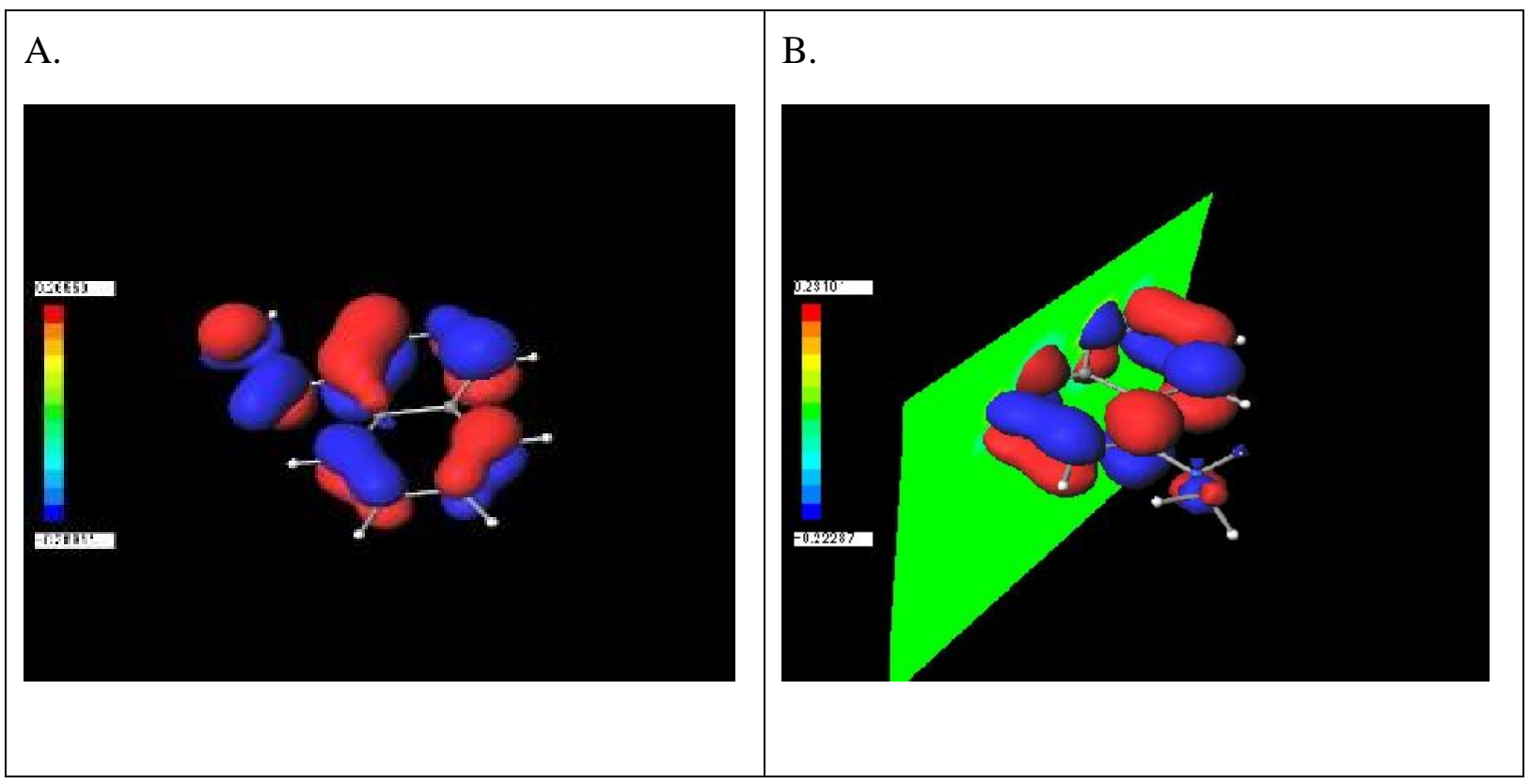

Fig.10. Structure of (A) HOMO energy state (B) LUMO energy state. 
Table 6. Quantum chemical parameters for Mild Steel in the absence and Presence of different concentrations of Hydralazine in $1 \mathrm{M} \mathrm{HCl}$.

\begin{tabular}{ccc}
\hline SI.No. & Quantum chemical Parameters & Results \\
\hline 1 & E $_{\text {HOMO }}(\mathrm{eV})$ & $-8.572 \mathrm{eV}$ \\
2 & ELUMO $_{\mathrm{LU}}(\mathrm{eV})$ & $-0.748 \mathrm{eV}$ \\
3 & $\mathrm{E}=\mathrm{E}_{\mathrm{LUMO}}-\mathrm{E}_{\mathrm{HOMO}}(\mathrm{eV})$ & $7.824 \mathrm{eV}$ \\
4 & Dipole Moment, & $1.98 \mathrm{debye}$ \\
\hline
\end{tabular}

\subsection{Scanning electron microscopy (SEM) analysis}

The surface morphology of the steel surface was viewed by SEM. Fig.11 shows that the SEM photograph of the steel surface. The SEM photographs showed that the surfaces of metal have pits and corrosive product, but in the presence of inhibitor, they are minimized on the metal surface. It indicates the formation of a passive layer on the metal surface by which corrosion rate decreases in the presence of inhibitor and diminishes the electrochemical reaction.

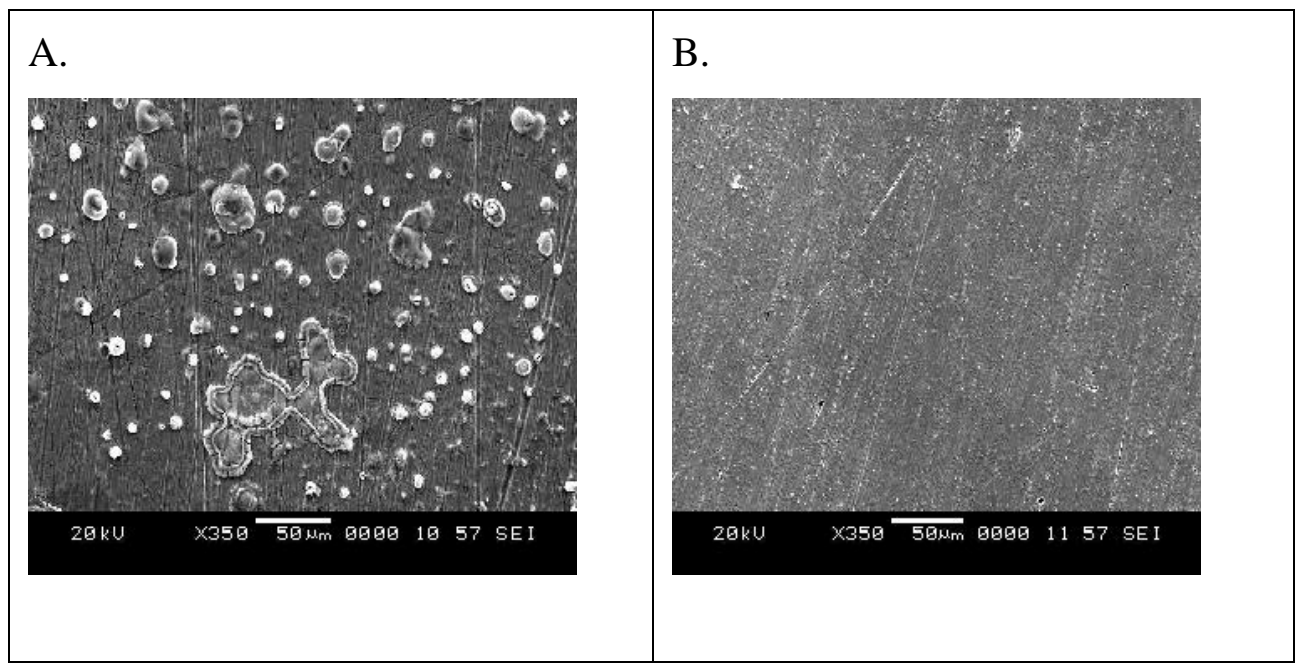

Fig.11. SEM Photographs of steel surface in (A) absence of inhibitor $(1 \mathrm{M} \mathrm{HCl})$ and (B) in Presence of inhibitor Hydralazine in $1 \mathrm{M} \mathrm{HCl}$ solution.

\section{EXPERIMENTAL}

Mild Steel strips with a composition of $0.04 \%$ C, $0.35 \% \mathrm{Mn}, 0.022 \% \mathrm{P}, 0.036 \% \mathrm{~S}$ and the rest being Fe (99.55\%) were used for all the measurements. Strips of dimension of $5 \mathrm{~cm} \mathrm{x} 1 \mathrm{~cm} \mathrm{x}$ $0.1 \mathrm{~cm}$ were used for weight loss method and same strips with an exposed area of $1 \mathrm{~cm}^{2}$ (rest 
is covered by araldite resign) for electrochemical measurements were used. The metal strips were abraded by emery paper with grade number 100 up to 2000 and washed thoroughly with double distilled water, degreased with acetone and dried at room temperature. The corrosive media $1 \mathrm{M} \mathrm{HCl}$ solutions were prepared by using analytical grade hydrochloric acid.

The IUPAC name of the Hydralazine is 1-hydrazinylphthalazine.The molecular structure of the inhibitor is as shown in Fig.12

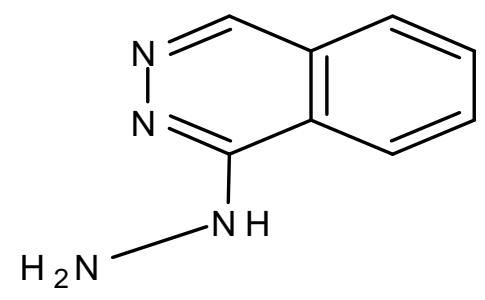

Fig.12. Molecular Structure of Hydralazine.

The weight loss measurement was carried out at $303 \mathrm{~K}$ temperature in absence and presence of various inhibitor concentrations over an immersion period of $4 \mathrm{hrs}$ in $1 \mathrm{M} \mathrm{HCl}$ solution. Mild steel strips were weighed before and after the immersion process and record the weight difference. Through the weight difference values, the corrosion rate $v\left(\mathrm{~g} \mathrm{~cm}^{-2} \mathrm{~h}^{-1}\right)$ was calculated from following equation,

$v=\frac{w^{\circ}-w}{w^{n}} \times 100$

where $\mathrm{W}^{0} \& \mathrm{~W}$ are the weight difference of the mild steel strips in absence and presence of inhibitor respectively. " $s$ " is the surface area of the steel strips and " $t$ " is the immersion time in hours. The inhibition efficiency $\left(\eta_{\mathrm{w}}\right)$ was calculated by using the following expression

$\eta_{w}=\frac{v-v_{i}}{v} \times 100$

where $v$ and $v_{i}$ are the corrosion rates of mild steel in absence and in presence of inhibitor in bulk of the solution respectively.

The electrochemical measurements were carried out with three electrode system by using CH-608D electrochemical work station. Usually three electrode system involves the working (Mild steel strip with $1 \mathrm{~cm}^{2}$ exposed area) electrode, counter (Platinum) electrode and a reference (saturated calomel) electrode was used for all the electrochemical measurements. In 
Tafel measurement, current-potential curves were recorded at a scan rate of $0.01 \mathrm{~V} / \mathrm{s}$ with given potential range. Impedance measurements were taken by using an AC signal with amplitude of $1 \mathrm{~m} \mathrm{V/s}$ at $\mathrm{OCP}$ in the frequency range from $10 \mathrm{kHz}$ to $0.1 \mathrm{~Hz}$.

Corrosion inhibiting effect takes place by the adsorption of Hydralazine on the surface of mild steel. In order to learn about the mode of adsorption process at different temperatures due to the surface coverage $(\theta)$ by the inhibitor molecule. For this electrochemical impedance spectroscopic data were made to fit with various adsorptions isotherm models. Results fit more comfortable regression co-efficient value almost near unity. This suggests that this adsorption process obeys the Langmuir's adsorption isotherm and thermodynamic parameters were computed by using standard equations.

The kinetics of the inhibition mechanism was studied by activation parameters for the corrosion process. Data obtained by electrochemical Tafel polarization measurement were used to investigate the activation parameters with the help of Arrhenius and Transition theory at different temperatures from $303-333 \mathrm{~K}$ in absence and presence of different concentrations of Hydralazine.

Quantum chemical parameters were computed to explain the structure and electronic properties and correlation with inhibition efficiency of inhibitor on the mild steel surface based on semi-empirical PM3 method by using hyperchem 7.5 package programmes.

The Surface analysis of the mild steel strip immersed in absence and presence of inhibitor was investigated by Scanning electron microscopic (JEOL JSM-840A model) graphs.

\section{ACKNOWLEDGEMENTS}

The authors are obliged to the authorities of Srinivas School of Engineering, Mukka, Mangalore, Karnataka, India for providing excellent lab facilities. The authors also express thanks to Department of Science and Technology, New Delhi, Govt. of India under the fast track scheme for young scientist [DST: Project Sanction No. SR/FT/CS-147 2011dated 13-07-2012] and All India Council for Technical Education, New Delhi, Govt. of India under MODROBS scheme [Ref. No 8024/RIFD/MOD 292 /2010-11 dated 31-03-2011] for providing instrumental amenities. 


\section{REFERENCES}

[1] Shukla S K, and Quraishi M A, (2010), Corros. Sci. 52,314-321.

[2] Aljourani J, Raeissi K, and Golozar M A,Corros Sci.,(2009),51,1836-1843.

[3] Fouda A S, Mostafa, H A, El-TaibF, and Elewady G Y, Corros Sci,(2005),47(8),1988-2004.

[4] Sathiyanarayanan S,Jeyaprabha C, Muralidharan S, and Venkatachari G,Appl Surf Sci,(2006),252,(23),8107-8112.

[5] Ouchrif A, Zegmout M, Hammouti B,El-Kadiri S,and Ramdani A,Appl Surf Sci, (2005), $252(2), 339-344$.

[6] Sathiyanarayanan S, Marikkannu C, and Palaniswamy N,Appl Surf Sci,(2005), $241,477-484$.

[7] Sudhish, K.S. and Quraishi M A, Mater Chem Phys,(2010),120(1),142-147.

[8] Trabanelli, G. (1991): Corrosion and surface chemistry of metals, 47: 410.

[9] Raicheva S N, Aleksiev B V and Sokolova, E.I.Corros, Sci., 1993, 34(2), 343-350.

[10] Arab, S. and Noor, E.A, Corrosion, 1993, 49(2), 122-129.

[11] Quraishi M A, Wajidkham M A, and Ajmal M, Bull.Electrochem.1995, 11(6), 274.

[12] Singh, A.and Choudhary R, S, Br Corros J,(1996), 31(4),300.

[13] Abd El-Rehim S S, Ibrahim M A M, and Khalid K F, J Appl Electrochem, (1999), 29 (5), 593-599.

[14] Quraishi M A, Sardar R, and Jamal O, Mater Chem Phys, (2001), 71 (3), 309-313.

[15] Yurt A, Balaban A, Ustin Kandemiv S,Bereket G, and Erx B, Mater Chem Phys.,(2005),85(2), 420-426.

[16] Ashassi-Sorkhabi H,Shaabani B, and Seifzadeh D,.Appl Surf Sci(2005), 239(2),154-164.

[17] Bentiss F, Traisnel M, Chaibi,N, Mernari B,Vezin H,and Lagrenee M,Corros Sci(2002), 44(10),2271-2289.

[18] Abd El-Rehim S S, Refaey S A M, Taha F, Saleh M B and Ahmed,R A,J Appl Electrochem,(2001), 31 (5),429-435.

[19] Tamil Selvi S, Raman V, and Rajendran N,(2003),33(12),1175-1182.

[20] Khamis E, Corrosion (1990), 476. 
[21] Stupnisek-Lisac E, and Metikos-Hukovia M, Br Corros J , (1993),28,74.

[22] Stupnisek-Lisac E, Podbrscek S and Soric T,J Appl Electrochem.(1994),24(8),779-784.

[23] Musa A Y, Kadhum A A H, Mohamad A B, and Takriff M S, Corros. Sci. (2010), 125(3), $3331-3340$.

[24] Ferreira E S, Giancomlli C, Giacomlli F C,and Spinelli A, Mater. Chem. Phys. (2004), 83,129-134.

[25] Singh A K, Shukla S K, Singh M and Quraishi M A, Mater. Chem. Phys. (2010), 129, 68-76.

[26] Benali O,Larabi L,Traisnel M, Gengembre L, and Harek Y,Applied Surface Science,(2007),253(140),6130-6139.

[27] Ostovari A, Hoseinieh S M, Peikari M, Shadizadeh S R, and Hashemi S, Corros. Sci. 2009, 51(9), 1935-1949.

[28] Prasanna,B.M.,Praveen B.M., Narayana Hebbar., Venkatesha,T.V., and Tandon, H.C., "Ketosulfone drug as a green corrosion inhibitor for Mild Steel in Acidic Medium", Ind. Eng. \& Chem. Res., Vol.53, pp 8436-8444.

\section{How to cite this article}

Prasanna B M. Praveen B M. Hebbar Narayana. Venkatesha T V. Anticorrosion potential of hydralazine for corrosion of mild steel in $1 \mathrm{~m}$ hydrochloric acid solution. J Fundam Appl Sci. 2015. 7(2). 222-243. 